\title{
Basic cellular and molecular mechanisms of anesthetic-induced developmental neurotoxicity: Potential strategies for alleviation
}

\author{
Padmaja Durga, Vidya Yalamanchili'
}

\begin{abstract}
There is an increasing concern regarding the risk of anesthetic-induced developmental neurotoxicity (AIDN) in children. Evidence has shown that exposure to most of the commonly used anaesthetic and sedatives can cause neurodegeneration in the developing brain. Anesthetic effects on the brain during its growth spurt can initiate a cascade of alterations in neurodevelopment, which can be detected structurally or functionally. Anesthetic exposure induces apoptosis and neurodegeneration in a dose and time-dependent fashion consistent with the pattern of $\mathrm{N}$-methyl $\mathrm{D}$-aspartate antagonism and gamma-amino butyric acid type $\mathrm{A}$ activation by these drugs. Understanding the cellular and molecular mechanisms of AIDN may help in developing methods that are safe and do not interfere with the beneficial properties of anaesthetic drugs and yet inactivate the intracellular signals that trigger neuroapoptosis.
\end{abstract}

Key words: Alleviation, anaesthesia, apoptosis, developmental, mechanism, neurobehavioral, neurodegeneration, neurotoxicity

\section{INTRODUCTION}

Children who require surgical interventions are exposed to several perioperative factors which could affect the brain and behavioral development such as psychological stress, pain and inflamatory response resulting from surgery and anaesthesia. ${ }^{[1]}$ There is an increasing concern regarding the risk of anaesthetic-induced developmental neurotoxicity (AIDN) in children. Exposure to all commonly used anesthetics and sedatives, with the possible exception of $\alpha 2$-adrenergic agonists, can cause neurodegeneration and cognitive dysfunction in the developing brain. Most of the studies attribute this neurotoxicity to neuroapoptosis and impairment of other

\begin{tabular}{|l|l|}
\hline \multicolumn{2}{|c|}{ Access this article online } \\
\hline Quick Response Code: & Website: \\
\hline & www.jnaccjournal.org \\
\cline { 2 - 2 } & \\
\hline & \\
\hline
\end{tabular}

neurodevelopmental processes such as neurogenesis, synaptogenesis, and glial development. The possibility of AIDN raises concerns regarding current anaesthesia practice for pregnant women, infants, and children. It is important to understand the molecular mechanisms underlying neurobehavioral abnormalities induced by anaesthetic exposure in early life and the potential therapies to mitigate these effects as they have a profound potential implication on clinical practice.

\section{PHYSIOLOGICAL BASIS FOR ENHANCED VULNERABILITY OF DEVELOPING BRAIN TO ANAESTHETIC NEURONAL TOXICITY}

Perinatal life and early childhood are the most intensive periods of brain development. There is a rapid increase in neuronal proliferation, differentiation, synaptogenesis, and dendritic development in the central nervous system of the foetus, infants, and children. The rate of change is greatest in the fetus and early childhood. Several trophic factors and receptors are involved

Department of Anaesthesiology and Intensive Care, Nizam's Institute of Medical Sciences, Hyderabad, Telangana, India, ${ }^{1}$ Department of Anaesthesiology, Emory University School of Medicine, Atlanta, Georgia, USA 
in development. However, neurons are produced in excess. It is estimated that $50-70 \%$ of the entire neuronal cell population is pruned during regular foetal and neonatal brain maturation. The brain is remodeled by physiological apoptosis during normal development. ${ }^{[2]}$ Disruption of the delicate balance between cell survival and apoptosis in the brain during the periods of rapid brain development may result in neurodevelopmental disorders.

Numerous studies in animals have shown that general anaesthetic agents not only induce neuroapoptosis, but also affect other neurodevelopmental processes in the developing brain. Preclinical studies demonstrated accelerated neuronal apoptosis in newborn rodents exposed to general anaesthetics such as ketamine, ${ }^{[3]}$ midazolam, ${ }^{[4]}$ propofol, ${ }^{[5]}$ nitrous oxide, ${ }^{[6]}$ sevoflurane, ${ }^{[7]}$ isoflurane, ${ }^{[8]}$ and desflurane ${ }^{[9]}$ It remains unclear whether anaesthesia induces apoptosis of cells otherwise not destined to die (i.e., pathological apoptosis), or whether it accelerates apoptosis of cells destined to die at a later time (i.e., premature physiological apoptosis). The effects of anaesthetics on neurons vary significantly relative to duration and timing of exposure, gestational age and species. The developing brain is more susceptible to anaesthetic-induced neurotoxicity compared with the mature brain. ${ }^{[10]}$ The effect of anaesthetics on apoptosis was greatest in 5-7 days old rats, which corresponds to mid-gestation to several years after birth in humans. ${ }^{[11]}$ Furthermore, more prolonged exposure to anaesthetics ${ }^{[12]}$ as well as exposure to multiple anaesthetic agents in combination $^{[4,13]}$ exacerbated the severity of the apoptosis. Even prenatal exposure to anesthetics can result in neurotoxicity. ${ }^{[12,14]}$ The understanding of molecular mechanisms underlying neurobehavioral abnormalities induced by anaesthetic exposure in early life and the potential therapies to mitigate these findings have potential implications in translating to paediatric and obstetrics anaesthesia practice. ${ }^{[15]}$

\section{MOLECULAR MECHANISMS OF NEURONAL TOXICITY IN DEVELOPING BRAIN}

The exposure to anaesthetics during the brain growth spurt period can initiate a cascade of alterations in neurodevelopmental cellular and molecular mechanisms [Figure 1], which can be detected structurally or functionally.

\section{NEUROAPOPTOSIS}

Apoptosis, or cell suicide, is an organized energy-consuming process by which "unwanted" cells are removed from the organ. Apoptosis involves chromatin aggregation, the condensation of cellular

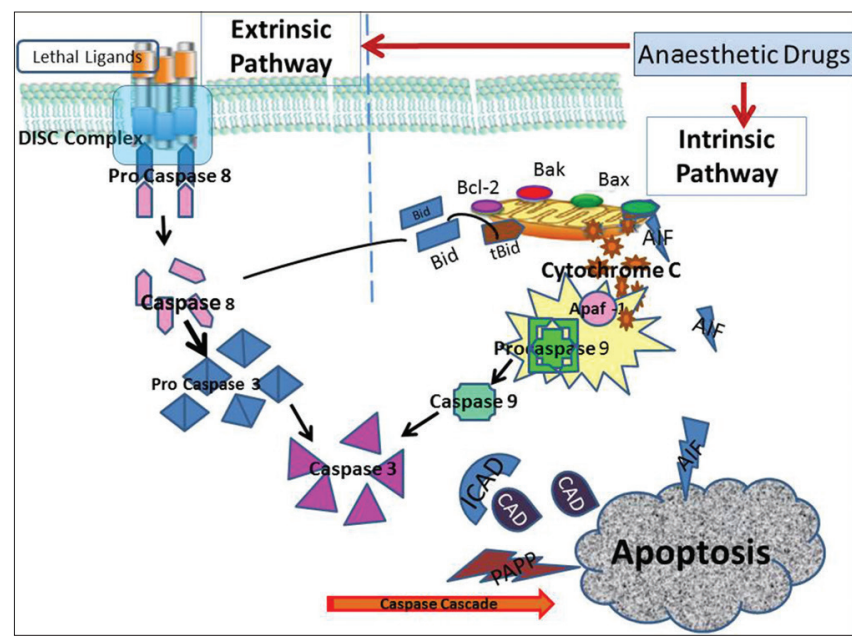

Figure 1: Intrinsic and extrinsic pathways of apoptosis-effect of anaesthetics

organelles, and the development of apoptotic bodies that are readily consumed by phagocytosis. Apoptosis may be triggered via two pathways: Intrinsic and extrinsic. Both pathways, however, share a final common sequence that identifies an important marker of apoptosis: Activation of the enzyme caspase- $3^{[16]}$ [Figure 1]. Many factors, physiological and pathological, can trigger apoptosis including normal growth and development, diseases, and anaesthetics. Although the underlying molecular mechanisms of anaesthetic-induced apoptosis are not completely understood, mitochondrial dysfunction, altered calcium homeostasis, and apoptosis-related proteins have been implicated. ${ }^{[17]}$

\section{ROLE OF N-METHYL D-ASPARTATE RECEPTORS AND GAMMA-AMINO BUTYRIC ACID TYPE A RECEPTORS}

Gamma-amino butyric acid (GABA) and N-methyl D-aspartate (NMDA) receptors are involved in normal brain development. The morphology and function of receptors during the developmental periods is different from the mature brain. The GABA and NMDA receptors are indirectly involved in the balance of activity and thus, the generation of trophic factors that drive cell proliferation, migration, differentiation, growth, dendritic maturation, and apoptosis. ${ }^{[13]}$ Most anaesthetics exert their action on GABA and NMDA receptors. Anaesthetic exposure induces apoptosis and neurodegeneration in a dose- and time-dependent fashion consistent with the pattern of NMDA antagonism and GABA type $\mathrm{A}\left(\mathrm{GABA}_{\mathrm{A}}\right)$ activation.

Glutamate, which has action on NMDA receptors, has trophic functions in the developing brain; it encourages cell growth, as well as certain aspects of neuronal development, including migration, differentiation, 
and plasticity. Neonatal neurons may be dependent upon NMDA receptor stimulation. The withdrawal or inhibition of NMDA receptor stimulation, therefore, triggers apoptosis. In humans, peak NMDA receptor expression is during weeks 20-22 of gestation. Therefore, exposure of the developing fetus or neonate to volatile anaesthetics can be considered the high risk for neuroapoptosis and neurodegeneration. Ketamine may also cause a compensatory up-regulation of NMDA receptors, subsequently triggering expression of apoptosis-related genes in the developing neurons. ${ }^{[18]}$ The toxic effects of NMDA receptor antagonists such as ketamine and some volatile agents on the immature brain in animal experiments have been extensively explored ${ }^{[3,19,20]}$ However, clinical evidence for ketamine neurotoxicity in children is inconclusive. ${ }^{[21-24]}$

The primary inhibitory neurotransmitter GABA is excitatory on immature neurons via its action at the $\mathrm{GABA}_{\mathrm{A}}$ receptor. In the adult, $\mathrm{GABA}_{\mathrm{A}}$ receptor activation leads to an influx of $\mathrm{Cl}$ ion into the cell resulting in hyperpolarization and possible neuroprotection. However, in the developing brain, especially during synaptogenesis, the intracellular concentration of $\mathrm{Cl}^{-}$is high. Activation of $\mathrm{GABA}_{\mathrm{A}}$ receptor results in $\mathrm{Cl}^{-}$efflux and depolarization of the neuron. Depolarization mediates rise in intracellular calcium concentration, which reaches levels that can contribute to neuronal injury. ${ }^{[25]}$ Currently, several anaesthetics, sedatives or anticonvulsants used clinically act on $\mathrm{GABA}_{\mathrm{A}}$ receptor as agonists. They could suppress postnatal neurogenesis, trigger widespread apoptotic cell death in developing brain and eventually result in long-term neurobehavioral impairment. ${ }^{[26,27]}$

The mechanism of cell death triggered by anaesthetic drugs involves translocation of Bax protein to mitochondrial membranes, where it disrupts membrane permeability, allowing extra-mitochondrial leakage of cytochrome c, followed by a sequence of changes culminating in activation of caspase-3 [Figure 2]. The specific steps in the upstream pathways through which the signal is relayed from the cell surface $\mathrm{GABA}_{\mathrm{A}}$ receptors to Bax protein remain to be identified. This can be a potential step in producing anesthetic state without triggering neurotoxicity.

The combination of a GABA agonist and NMDA antagonist has been shown to cause more widespread neurodegeneration in neonatal animals than individual agents. ${ }^{[4,13]}$

\section{MITOCHONDRIAL PERTURBATIONS}

Mitochondrial impairment may be central in anaesthetic-induced acute neuroapoptosis and cognitive

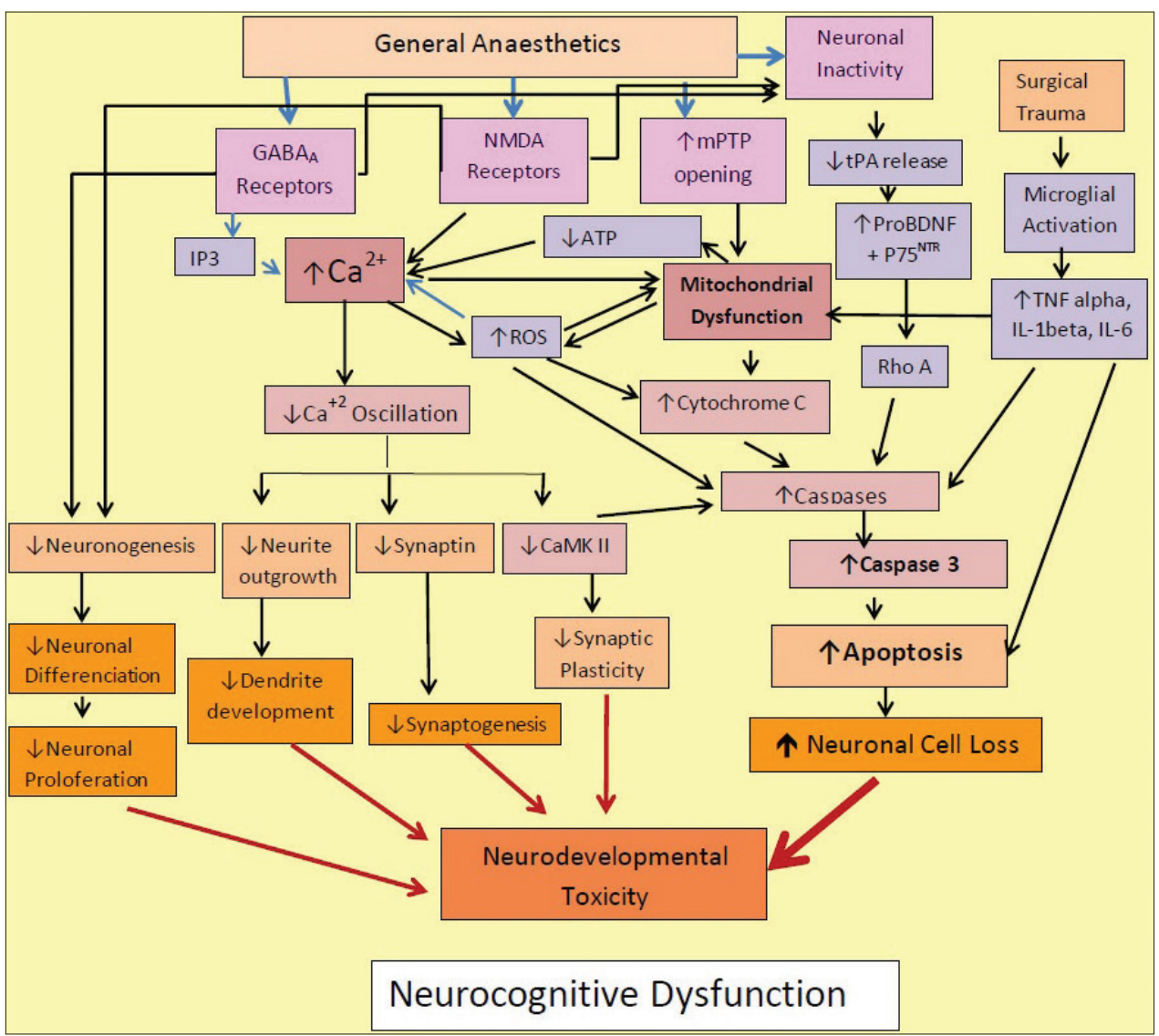

Figure 2: Summary of cellular and molecular mechanisms of anaesthetic-induced developmental neurotoxicity 
abnormalities in later life. Anaesthesia can impair mitochondrial morphogenesis, integrity and function at the peak of synaptogenesis. Anaesthetics induce neurotoxicity through opening of the mitochondrial permeability transition pore (mPTP) and reduction in mitochondrial membrane potential. ${ }^{[28-31]}$ Lowered mitochondrial transmembrane potential and increased cytosolic free calcium $\left(\mathrm{Ca}^{2+}\right)$ after exposure significantly decrease the expression of the anti-apoptotic protein (Bcl-2), increase expression of proapoptotic protein bax and stimulate the release of cytochrome-C. This activates mitochondrial apoptotic pathway by activating caspase- 9 and caspase- 3 leading to DNA fragmentation and neuronal death [Figure 2].

Mitochondria are both a major source of oxygen free radicals and also a target for free radical attack. Mitochondria-dependent pathway also involves anaesthesia induced up-regulation of reactive oxygen species (ROS) leading to the excessive lipid peroxidation of lipid membranes and damage to neuronal organelles, mitochondria, and endoplasmic reticulum (ER) in particular. The ER-dependent pathway involves anaesthesia-induced activation of inositol 1,4,5-trisphosphate receptors (InsP3R) leading to the excessive $\mathrm{Ca}^{2+}$ release and acute elevation of cytosolic $\mathrm{Ca}^{2+}{ }^{\left[{ }^{[32]}\right.}$ Nicotinic acid adenine dinucleotide phosphate (NAADP) gated two-pore channels (TPCs) control $\mathrm{Ca}^{2+}$ uptake into the lysosomes. An increase in the intra-lysosomal level of $\mathrm{Ca}^{2+}$ activates lysosomal activity, which in turn promotes lysosomal and autophagosomal fusion, the formation of autophagic vacuoles and neuronal "self-eating." Although it is proposed that anaesthesia causes lysosomal activation indirectly via an increase in cytosolic $\mathrm{Ca}^{2+}$ from the ER, it remains unclear whether anaesthesia has a direct effect on lysosomal activation (via NAADP-gated TPCs in particular).

\section{DYSREGULATION OF INTRACELLULAR $\mathrm{CA}^{2+}$ HOMEOSTASIS}

Calcium dysregulation promotes several events including mitochondrial dysfunction, growth cone collapse (resulting in reduced neurite length and complexity), changes in expression of proteins related to the cytoskeleton and synapse and production of neurotransmitters. Volatile anaesthetics including isoflurane and sevoflurane could induce intracellular calcium overload, which increases ROS and NO levels that could result in neuroapoptosis. Isoflurane potentiates $\mathrm{GABA}_{\mathrm{A}}$ receptor-mediated synaptic voltage-dependent calcium channels and enhances the GABA-induced $\mathrm{Ca}^{2+}$ increase. ${ }^{[26]}$

$\mathrm{Ca}^{2+}$ oscillation is the periodical increase and decrease of intracellular $\mathrm{Ca}^{2+}$ concentration. $\mathrm{Ca}^{2+}$ oscillation can interact with the neuronal nuclear transcriptional machinery. In the immature brain, $\mathrm{Ca}^{2+}$ oscillation plays an important role in neuronal differentiation, synaptogenesis, neuronal network development and plasticity. ${ }^{[33]}$ Calcium oscillations increase CaMK II levels, which would then promote neuronal synaptic plasticity, and synapsin levels improving neuronal synaptogenesis and cell survival pathways. ${ }^{[34]}$ Interference of $\mathrm{Ca}^{2+}$ oscillation via the NMDA receptor or persistent intracellular $\mathrm{Ca}^{2+}$ concentration affects neuronal synaptogenesis and also leads to neuronal apoptosis. ${ }^{[34]}$

\section{NEURO-INFLAMMATORY PATHWAY}

Recent findings suggest that neuro-inflammatory mediators such as cytokines may be involved in a number of key steps in the pathological cascade of events leading to anaesthetic-induced neuronal injury. ${ }^{[35,36]}$ Both anaesthesia and surgery can induce cytokines release in the central nervous system, leading to deleterious neurodevelopmental effects. Activation of microglia and astrocytes by surgical and other stress causes production of the pro-inflammatory factors and up-regulation of NADPH oxidase, which result in generation of ROS and disruption of mitochondrial membrane potential. ${ }^{[17]}$ Nociceptive stimulation (e.g., surgical incision) with prolonged anaesthesia exposure produces significantly more apoptosis than prolonged anaesthesia alone in neonates during the synaptogenic period. ${ }^{[37]}$

\section{THE BRAIN-DERIVED NEUROTROPHIC FACTOR PATHWAY}

Since, every anaesthetic agent has the potential to induce apoptosis in neonatal neurons; it has been proposed that anaesthetic state itself promotes apoptosis. Neurotrophins such as brain-derived neurotrophic factor (BDNF) are chemicals of central importance in the regulation of the survival, differentiation, and maintenance of functions as synaptic plasticity in the developing brain. Evidence has shown that general anaesthetics induce neuro-apoptotic damage in the developing brain, at least in part via the BDNF modulated apoptotic cascade. ${ }^{[38,39]}$ The anaesthetic suppression of spontaneous neuronal activity might lead to insufficient neurotrophic factor secretion in the developing nervous system. ${ }^{[40]}$ Active axons normally release tissue plasminogen activator (tPA) and proBDNF. The tPA cleaves plasmin to plasminogen, which in turn converts proBDNF to BDNF. BDNF acts at the TrkB receptor, resulting in the activation of a variety of signaling mechanisms that enhance neuronal survival. If the axon is not active, proBDNF but not $\mathrm{PPA}$, continues to be released. Without tPA, there is no plasminogen, and thus proBDNF is not converted to BDNF. The proBDNF acts on the p75 NTR receptor on the dendrite, which results in cell death ${ }^{[41]}$ [Figure $3 a$ and $b$ ]. The relative inactivity results in a loss of trophic factors 


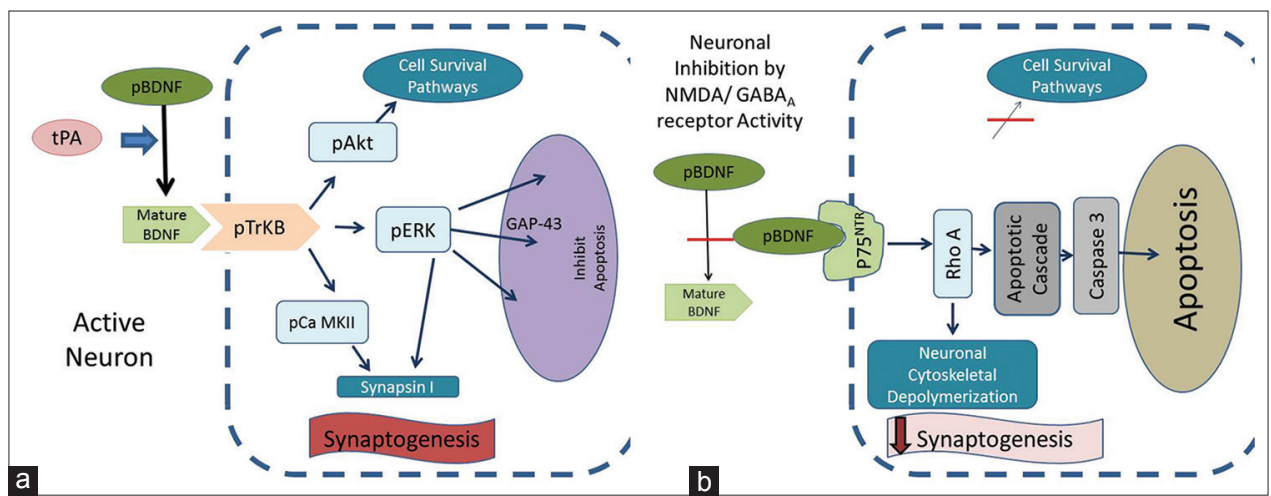

Figure 3: (a) Role of brain-derived neurotrophic factor-active neuron (b) role of brain-derived neurotrophic factor-inactive neuron

which in turn triggers apoptosis. This theory fits with the "use it or lose it" notion. If anaesthetic-induced suppression of electrophysiological activity occurs during critical developmental periods, neurons that are pharmacologically "disconnected" from the network might be pruned through apoptotic mechanisms. It is possible that anaesthesia induces inactivity via $\mathrm{GABA}_{\mathrm{A}}$ and NMDA receptors.

\section{OTHER CELLULAR PROCESSES IN ANESTHETIC INDUCED DEVELOPMENTAL NEUROTOXICITY}

\section{Neurogenesis}

Anaesthetics can cause the inhibition of maturation and proliferation of neuronal progenitor cells..$^{[42,43]}$ decrease the pool of neural stem cells and decrease their self-renewal capacity. ${ }^{[4]}$ The inflammatory cytokines induced by general anaesthetics may also impair neural progenitor cells proliferation and alter their differentiation. ${ }^{[45]}$ These changes could adversely result in late cognitive dysfunction after general anaesthesia in age-dependent manner. ${ }^{[46]}$

\section{Dendritic development}

The dendritic spines are the postsynaptic sites of most excitatory axodendritic synapses in the brain. Genesis of dendritic filopodia and spines formation play a critical role in synaptogenesis. Impairment of synaptogenesis potentially interferes with the development of neural networks. Recent studies from fixed brain preparations have shown that exposure to isoflurane and ketamine ${ }^{[4]}$ decreases synapse or spine density in hippocampus of neonatal rodents. On the other hand, some studies have shown that exposure to anaesthetics midazolam, propofol, or ketamine causes a significant increase in the density of dendritic spines. ${ }^{[48]}$ The effects of anaesthetic exposure on synaptic connectivity in the brain may depend on developmental stage leve ${ }^{[49]}$ and the dose of anaesthetics. ${ }^{[50]}$ The mechanisms underlying the effects of anesthetics on synaptogenesis remain unclear, but at least may, in part, involve blockade of NMDA receptor activity or potentiation of $\mathrm{GABA}_{\mathrm{A}}$ receptor activity.

\section{Neurite outgrowth}

The effects of anesthetics on neurite outgrowth are reversible and transient. ${ }^{[51,52]}$ This makes anaesthetics unlikely to induce cognitive dysfunction by this mechanism.

\section{Glial development}

Astrocytes, the most abundant glial cells in the brain, are necessary for the formation, function, stability and plasticity of synapses. Anaesthetics may interfere at multiple levels to impair proper cytoskeletal development early, thereby disturbing glial growth and maturation. ${ }^{[53]}$ The susceptibility of glial cells to anesthetic toxicity is age-dependent as well. The lethal anesthetic dose for immature glial cells and neural stem cells is greater than that for developing neurons.

\section{Neural stem cell}

A study on human neural stem cells showed that they are more resistant to cell apoptosis than neurons. The neural stem cells express fewer NMDA receptors, which explain the difference in cell susceptibility to ketamine-induced toxicity.

\section{CURRENT EVIDENCE ON NEONATAL NEUROTOXICITY IN HUMANS}

Several animal studies have shown the relationship between anaesthesia and neurotoxicity, it is difficult to evaluate the effect in humans. There is a paucity of randomized clinical trials in this area due to ethical constraints. Despite the inherent limitations of observational cohort studies, several human cohort studies suggest an association between early exposure to anesthetics and poor cognitive performance in later life. ${ }^{[15,22,54-59]}$ Those children receiving anaesthesia before 3 years of age are more likely to have learning and behavior disorders compared with peers without anaesthesia ${ }^{[6,66]}$ Exposure to anaesthesia in early life more 
than once or for a prolonged period adversely affects long-term neurodevelopmental outcomes in children. ${ }^{[55,62]}$ However, language and cognition deficits are reported even after a single anaesthetic exposure. ${ }^{[63]}$ Even foetal exposure to anaesthetics has also been associated with a variety of behavioral and psychiatric disturbances that persist into adulthood, including hyperactivity and attention deficit hyperactivity disorder. ${ }^{[55,64]}$ Based on these studies, it may be reasonable to speculate that neuropathological changes observed in the developing brain of animals similarly occur in brains of infants and children after anaesthesia. However, some studies have shown no association between early anaesthetic exposure/surgery and the development of cognitive or behavioral disturbances. ${ }^{[5,59,61,65]}$ Human neurobehavior is undoubtedly complex, and it is possible that the subtle impairments in neurobehavior resulting from anaesthesia are not easily detected through current neuropsychological and neurobehavioral tests.

The currently available retrospective cohort studies in humans have some limitations to provide conclusive evidence. Since children in all of these studies had surgery, it is difficult to separate the effects of co-morbidities, stress of surgery, ${ }^{[1]}$ burden of illness (e.g., absenteeism from school) on learning, cognition or behavior from anesthetic effects. Painful stimuli without analgesia and anaesthesia have also been shown to initiate a harmful stress response in young children and to trigger neurotoxic effects in the developing brain, which can be blunted by anesthetics. ${ }^{[15]}$ The ongoing studies may clarify a few of these issues. GAS study (A Multi-site Randomized Controlled Trial Comparing Regional and General Anaesthesia for Effects on Neurodevelopmental Outcome and Apnoea in Infants) ${ }^{[66]}$ performed on infants requiring inguinal herniorrhaphy will attempt to separate the effects of general anaesthesia from the surgical procedure. MASK (Mayo Anaesthesia Safety in Kids) study is a large cohort study long-term cognitive development of children with no anaesthetic exposure to those with single or multiple exposures prior to age 3 years. The presence of several social and environmental confounding factors and long lag time may also influence the results. Paediatric Anaesthesia NeuroDevelopmental Assessment Study has undergone a feasibility study ${ }^{[67]}$ and is currently in the late planning stages. It compares a retrospective cohort of children who received anaesthesia at $<3$ years of age with un-anaesthetized siblings in a prospective assessment of neurocognitive outcome in an attempt to reduce genetic and environmental contributions to cognitive performance. ${ }^{[67,68]}$

The possibility of AIDN has potential implications for current anaesthesia practice for pregnant women, infants and children. Moreover, if it is finally concluded that anesthetic drugs do injure the developing brains, we would be confronted with the big question of what can be done about it? It is, therefore, essential to develop and explore clinically relevant neuroprotective strategies in animals that are likely to mitigate the neurotoxic effects of anesthetics.

\section{METHODS OF PROTECTION AGAINST ANAESTHETIC-INDUCED NEUROTOXICITY-THEIR CELLULAR AND MOLECULAR MECHANISMS OF NEUROPROTECTION}

Most commonly used anaesthetics have shown neurotoxic properties in preclinical studies. Several molecular mechanisms are involved in the anaesthetic-induced neurotoxicity and cognitive dysfunction. Arresting the chain reaction may allow anesthetic drugs to depress reversibly the neurons without triggering unwarranted cell suicide signal. Many researchers have studied for the potentially mitigating or neuroprotective strategies to prevent the histologic and developmental abnormalities induced by anaesthetics. Peri-anaesthesia treatment with an ROS scavenger or mitochondria protectant prevented anaesthesia-induced cognitive impairment. Other mechanisms of action have also been identified. Several compounds, such as erythropoietin (EPO) ${ }^{\left[{ }^{[6]}\right]}$ lithium, ${ }^{[70,71]}$ melatonin, ${ }^{[72]} 7$-nitroindazole,${ }^{[73]} \mathrm{L}$-carnitine, ${ }^{[74]}$ bumetanide ${ }^{[75,76]}$ dexmedetomidine, ${ }^{[77,78]}$ and xenon, ${ }^{[79,80]}$ have been found to decrease anaesthetic-induced neurodegeneration in the developing brain.

\section{Alpha2 adrenoceptor agonist}

Alpha2 adrenoceptor signaling plays a trophic role during neurodevelopment and is neuroprotective in several settings of neuronal injury. Dexmedetomidine neuroprotection appears to involve a decrease in cleaved caspase-3 levels, and reversal of isoflurane-induced decrease in anti-apoptotic Bcl-1, pERK1, and pERK2 protein expression in vivo. ${ }^{[81]}$ Neuroprotective mechanisms of $\alpha 2$ adrenoceptor signaling also involve inhibition of calcium entry, scavenging of glutamate, and reduction in NMDA receptor activation. ${ }^{[82]}$

\section{Xenon}

Although an antagonist at the NMDA type glutamate receptor, xenon pretreatment exerted neuroprotectant effect. Xenon's neuroprotective effect may be through its ability to inhibit intrinsic and common apoptotic pathways. ${ }^{[83]}$ At low concentrations, in animal models, it increased Bcl-2 expression and decreased both cytochrome $\mathrm{C}$ release and $\mathrm{P} 53$ expression ${ }^{[80]}$ and attenuated the neurotoxicity of isoflurane. ${ }^{[79,80]}$ However, an equipotent comparison of xenon and halogenated anesthetics causes cell death in developing neurons comparable to isoflurane and sevoflurane. ${ }^{[84]}$ 


\section{Brain preconditioning with anaesthetic}

Prior exposure to low dose of anaesthesia, or a shorter duration of anaesthetic exposure, can attenuate injury from high dose or prolonged anaesthetic exposure in the developing brain. ${ }^{[85]}$ Preconditioning with isoflurane, ${ }^{[86]}$ propofol ${ }^{[87]}$ can protect from anaesthetic-induced neurotoxicity. Sub-anesthetic doses of ketamine attenuated cell death and provided some degree of neuroprotection ${ }^{[88]}$ Pretreatment with xenon can also attenuate AIDN. ${ }^{[79]}$

\section{Vitamins}

Nicotinamide attenuates ketamine-induced neuronal cell loss in the developing rat brain. ${ }^{[89]}$ This reduced neuroapoptosis involves downregulation of Bax, inhibition of cytochrome c release from mitochondria into the cytosol, and reduction in activated caspase-3 levels. Nicotinamide is also a potent inhibitor of proinflammatory cytokines. It may inhibit the isoflurane-induced increase in levels of pro-inflammatory factors tumor necrosis factor alpha, interleukin-6 (IL-6), and IL-1 $\beta$, thus protecting from neurodevelopmental disorders. Vitamin D3 (1- $\alpha$-2, 5-dihydroxy-vitamin D3) can also protect against ketamine-induced neuroapoptosis. Vitamin D3 can induce CaBP expression or enhance trophic factor action, both of which can stabilize intracellular calcium. ${ }^{[90]}$ Vitamin C, an antioxidant may also be effective against AIDN. ${ }^{[91]}$

\section{Erythropoietin}

Erythropoietin could have a direct neurotrophic and neuroprotective effect, particularly in conditions of neural damage, influence the release of neurotransmitters and play an important role in synaptic plasticity. ${ }^{[92]}$ Anaesthetics may inhibit EPO production, resulting in neurotoxicity. ${ }^{[93]}$ The role of EPO needs to be established. ${ }^{[69]}$

\section{Lithium}

lithium, as a (glycogen synthase kinase- $3 \beta$ ) inhibitor, has shown protective effects against neuroapoptosis induced by drugs. ${ }^{[71]}$ Lithium treatment can also significantly increase BDNF serum levels, and suppress neuroapoptosis in the central nervous system through the BDNF-Akt-Bcl2 antiapoptotic signaling pathway.

\section{Melatonin}

Neuroprotective effect may be mediated by inhibition of mitochondria-dependent apoptotic pathway. ${ }^{[72]}$

\section{Acetyl-L-carnitine}

It is metabolized in the brain to acetyl coenzyme A, which subsequently enters the tricarboxylic acid cycle. It has been found to effectively block neuronal apoptosis caused by exposure to a combination of $\mathrm{N} 2 \mathrm{O}$ and isoflurane. ${ }^{[74]}$
Activity-dependent neuroprotective protein Injection of NAP can inhibit anaesthetic-induced caspase levels in dose-dependent manner. ${ }^{[94]}$

\section{Bumetanide}

Bumetanide is an inhibitor of the $\mathrm{Cl}^{-}$importer NKCC $\left(\mathrm{Na}^{+}-\mathrm{K}^{+}-2 \mathrm{Cl}^{-}\right.$co-transporter) treatment, which suppresses depolarizing GABAergic responses. ${ }^{[75,76]}$

\section{Other drugs}

Cyclosporine A, Magnesium, and propofol have shown to attenuate the isoflurane-induced MPTP opening, caspase- 3 activation, and impairment of learning and memory by inhibition of mPTP opening. ${ }^{[95]}$

The ability to pharmacologically render the patients insensitive to neurotoxic effects of anesthetics will be a big breakthrough. A better understanding of the mechanisms of AIDN will certainly identify such candidate drugs and techniques

\section{LIMITATIONS OF TRANSLATING ANIMAL RESEARCH TO HUMANS}

The evidence for neurotoxicity of anaesthetics on animals and mitigating drugs and techniques exists in the form of preclinical rodent studies. Its translation to humans has been criticized. ${ }^{[11]}$ The brain growth spurt period and period of vulnerability varies with species. The anesthetic exposure in preclinical studies does not compare with paediatric anaesthesia practice Most experiments on rodents were conducted with lack of control of physiological variables such as acid-based disturbances, hypoxia, starvation, which can have negative influence on neurons. The other limitations of these experiments were the lack of painful stimulus and higher plasma concentration of anaesthetics administered. Given the ethical and societal constraints, randomized controlled trials mirroring the experimental designs used in rodent models are not possible. There are no detectable clinical markers of neurodegeneration in children after exposure to anaesthetics. Non-human primate studies may address many of these concerns. Using monitoring standards similar to that of children undergoing operative procedures, seven studies have reported not only neuroapoptosis, but also other wider mechanisms of injury including degeneration of oligodendrocytes, neuro-inflammation, and impairment of both synaptogenesis and neurogenesis, ${ }^{[3,12,19,96-100]}$ which reinforce our concerns of AIDN in humans. However, we should exercise caution when extrapolating animal data to humans until more data is available.

\section{CONCLUSION}

The evidence for anaesthesia-induced neurodegeneration in animal models is compelling and has suggested the 
possibility for deleterious effects of anaesthetics in paediatric patients. All currently clinically utilized anesthetic drugs have been found to induce neuronal cell death in the developing brain and to potentially cause long-term neurological impairment. The exact molecular mechanisms neuronal toxicity of general anaesthetics and sedatives on developing brain is being intensely researched. Further laboratory work remains to be done to elucidate the agents, doses, and growth periods that may pose greatest risk, as well as possible methods to reduce such toxicity. The methods that inactivate the intracellular signals that trigger neurotoxicity and provide anaesthesia safely without interfering with the beneficial properties of anesthetic drugs are under development. The mechanisms and human applicability of anaesthetic neurotoxicity and neuroprotection needs further investigation.

\section{REFERENCES}

1. Borsook D, George E, Kussman B, Becerra L. Anesthesia and perioperative stress: Consequences on neural networks and postoperative behaviors. Prog Neurobiol 2010;92:601-12.

2. de la Rosa EJ, de Pablo F. Cell death in early neural development: Beyond the neurotrophic theory. Trends Neurosci 2000;23:454-8.

3. Zou X, Patterson TA, Divine RL, Sadovova N, Zhang X, Hanig JP, et al. Prolonged exposure to ketamine increases neurodegeneration in the developing monkey brain. Int J Dev Neurosci 2009;27:727-31.

4. Young C, Jevtovic-Todorovic V, Qin YQ, Tenkova T, Wang $\mathrm{H}$, Labruyere $\mathrm{J}$, et al. Potential of ketamine and midazolam, individually or in combination, to induce apoptotic neurodegeneration in the infant mouse brain. $\mathrm{Br} \mathrm{J}$ Pharmacol 2005;146:189-97.

5. Creeley C, Dikranian K, Dissen G, Martin L, Olney J, Brambrink A. Propofol-induced apoptosis of neurones and oligodendrocytes in fetal and neonatal rhesus macaque brain. Br J Anaesth 2013;110 Suppl 1:i29-38.

6. Savage S, Ma D. The neurotoxicity of nitrous oxide: The facts and "putative" mechanisms. Brain Sci 2014;4:73-90.

7. Istaphanous GK, Howard J, Nan X, Hughes EA, McCann JC, McAuliffe JJ, et al. Comparison of the neuroapoptotic properties of equipotent anesthetic concentrations of desflurane, isoflurane, or sevoflurane in neonatal mice. Anesthesiology 2011;114:578-87.

8. Liang G, Ward C, Peng J, Zhao Y, Huang B, Wei H. Isoflurane causes greater neurodegeneration than an equivalent exposure of sevoflurane in the developing brain of neonatal mice. Anesthesiology 2010;112:1325-34.

9. Kodama M, Satoh Y, Otsubo Y, Araki Y, Yonamine R, Masui $\mathrm{K}$, et al. Neonatal desflurane exposure induces more robust neuroapoptosis than do isoflurane and sevoflurane and impairs working memory. Anesthesiology 2011;115:979-91.

10. Zhu C, Gao J, Karlsson N, Li Q, Zhang Y, Huang Z, et al. Isoflurane anesthesia induced persistent, progressive memory impairment, caused a loss of neural stem cells, and reduced neurogenesis in young, but not adult, rodents. J Cereb Blood Flow Metab 2010;30:1017-30.

11. Soriano SG, Anand KJ, Rovnaghi CR, Hickey PR. Of mice and men: Should we extrapolate rodent experimental data to the care of human neonates? Anesthesiology 2005;102:866-8.

12. Slikker W Jr, Zou X, Hotchkiss CE, Divine RL, Sadovova N, Twaddle NC, et al. Ketamine-induced neuronal cell death in the perinatal rhesus monkey. Toxicol Sci 2007;98:145-58.

13. Fredriksson A, Pontén E, Gordh T, Eriksson P. Neonatal exposure to a combination of $\mathrm{N}$-methyl-D-aspartate and gamma-aminobutyric acid type A receptor anesthetic agents potentiates apoptotic neurodegeneration and persistent behavioral deficits. Anesthesiology 2007;107:427-36.

14. Xiong M, Li J, Alhashem HM, Tilak V, Patel A, Pisklakov S, et al. Propofol exposure in pregnant rats induces neurotoxicity and persistent learning deficit in the offspring. Brain Sci 2014;4:356-75.

15. Davidson A, Flick RP. Neurodevelopmental implications of the use of sedation and analgesia in neonates. Clin Perinatol 2013;40:559-73.

16. Yon JH, Daniel-Johnson J, Carter LB, Jevtovic-Todorovic V. Anesthesia induces neuronal cell death in the developing rat brain via the intrinsic and extrinsic apoptotic pathways. Neuroscience 2005;135:815-27.

17. Qin L, Crews FT. NADPH oxidase and reactive oxygen species contribute to alcohol-induced microglial activation and neurodegeneration. J Neuroinflammation 2012;9:5.

18. Liu F, Paule MG, Ali S, Wang C. Ketamine-induced neurotoxicity and changes in gene expression in the developing rat brain. Curr Neuropharmacol 2011;9:256-61.

19. Zou X, Liu F, Zhang X, Patterson TA, Callicott R, Liu S, et al. Inhalation anesthetic-induced neuronal damage in the developing rhesus monkey. Neurotoxicol Teratol 2011;33:592-7.

20. Jin J, Gong K, Zou X, Wang R, Lin Q, Chen J. The blockade of NMDA receptor ion channels by ketamine is enhanced in developing rat cortical neurons. Neurosci Lett 2013;539:11-5.

21. Bhutta AT, Schmitz ML, Swearingen C, James LP, Wardbegnoche WL, Lindquist DM, et al. Ketamine as a neuroprotective and anti-inflammatory agent in children undergoing surgery on cardiopulmonary bypass: A pilot randomized, double-blind, placebo-controlled trial. Pediatr Crit Care Med 2012;13:328-37.

22. Dong C, Anand KJ. Developmental neurotoxicity of ketamine in pediatric clinical use. Toxicol Lett 2013;220:53-60.

23. Yan J, Jiang H. Dual effects of ketamine: Neurotoxicity versus neuroprotection in anesthesia for the developing brain. J Neurosurg Anesthesiol 2014;26:155-60.

24. Yan J, Li YR, Zhang Y, Lu Y, Jiang H. Repeated exposure to anesthetic ketamine can negatively impact neurodevelopment in infants: A prospective preliminary clinical study. J Child Neurol 2014;29:1333-8.

25. Ben-Ari Y. Excitatory actions of gaba during development: The nature of the nurture. Nat Rev Neurosci 2002;3:728-39.

26. Zhao YL, Xiang Q, Shi QY, Li SY, Tan L, Wang JT, et al. GABAergic excitotoxicity injury of the immature hippocampal pyramidal neurons' exposure to isoflurane. Anesth Analg 2011;113:1152-60.

27. Zhang X, Paule MG, Wang C, Slikker W Jr. Application of microPET imaging approaches in the study of pediatric anesthetic-induced neuronal toxicity. J Appl Toxicol 2013;33:861-8.

28. Zhang Y, Dong Y, Wu X, Lu Y, Xu Z, Knapp A, et al. The mitochondrial pathway of anesthetic isoflurane-induced apoptosis. J Biol Chem 2010;285:4025-37.

29. Boscolo A, Starr JA, Sanchez V, Lunardi N, DiGruccio MR, Ori $\mathrm{C}$, et al. The abolishment of anesthesia-induced cognitive impairment by timely protection of mitochondria in the developing rat brain: The importance of free oxygen radicals and mitochondrial integrity. Neurobiol Dis 2012;45:1031-41.

30. Zhang Y, Xu Z, Wang H, Dong Y, Shi HN, Culley DJ, et al. Anesthetics isoflurane and desflurane differently affect mitochondrial function, learning, and memory. Ann Neurol 2012;71:687-98. 
31. Kajimoto M, Atkinson DB, Ledee DR, Kayser EB, Morgan PG, Sedensky MM, et al. Propofol compared with isoflurane inhibits mitochondrial metabolism in immature swine cerebral cortex. J Cereb Blood Flow Metab 2014;34:514-21.

32. Komita M, Jin H, Aoe T. The effect of endoplasmic reticulum stress on neurotoxicity caused by inhaled anesthetics. Anesth Analg 2013;117:1197-204.

33. Gao ZY, Chen M, Collins HW, Matschinsky FM, Lee VM, Wolf BA. Mechanisms of spontaneous cytosolic $\mathrm{Ca}^{+}$ transients in differentiated human neuronal cells. Eur J Neurosci 1998;10:2416-25.

34. Sinner B, Friedrich O, Zink W, Zausig Y, Graf BM. The toxic effects of $\mathrm{s}(+)$-ketamine on differentiating neurons in vitro as a consequence of suppressed neuronal $\mathrm{Ca}^{+}{ }^{+}$oscillations. Anesth Analg 2011;113:1161-9.

35. Dong Y, Wu X, Xu Z, Zhang Y, Xie Z. Anesthetic isoflurane increases phosphorylated tau levels mediated by caspase activation and $A ß$ generation. PLoS One 2012;7:e39386.

36. Wu X, Lu Y, Dong Y, Zhang G, Zhang Y, Xu Z, et al. The inhalation anesthetic isoflurane increases levels of proinflammatory TNF- $\alpha$, IL-6, and IL-1ß. Neurobiol Aging 2012;33:1364-78.

37. Shu Y, Zhou Z, Wan Y, Sanders RD, Li M, Pac-Soo CK, et al. Nociceptive stimuli enhance anesthetic-induced neuroapoptosis in the rat developing brain. Neurobiol Dis 2012;45:743-50.

38. Lu LX, Yon JH, Carter LB, Jevtovic-Todorovic V. General anesthesia activates BDNF-dependent neuroapoptosis in the developing rat brain. Apoptosis 2006;11:1603-15.

39. Popic J, Pesic V, Milanovic D, Todorovic S, Kanazir S, Jevtovic-Todorovic $\mathrm{V}$, et al. Propofol-induced changes in neurotrophic signaling in the developing nervous system in vivo. PLoS One 2012;7:e34396.

40. Olney JW, Young C, Wozniak DF, Ikonomidou C, Jevtovic-Todorovic V. Anesthesia-induced developmental neuroapoptosis. Does it happen in humans? Anesthesiology 2004;101:273-5.

41. Head BP, Patel HH, Niesman IR, Drummond JC, Roth DM, Patel PM. Inhibition of p75 neurotrophin receptor attenuates isoflurane-mediated neuronal apoptosis in the neonatal central nervous system. Anesthesiology 2009;110:813-25.

42. Hirasawa $T$, Wada $H$, Kohsaka S, Uchino S. Inhibition of NMDA receptors induces delayed neuronal maturation and sustained proliferation of progenitor cells during neocortical development. J Neurosci Res 2003;74:676-87.

43. Tung A, Herrera S, Fornal CA, Jacobs BL. The effect of prolonged anesthesia with isoflurane, propofol, dexmedetomidine, or ketamine on neural cell proliferation in the adult rat. Anesth Analg 2008;106:1772-7.

44. Culley DJ, Boyd JD, Palanisamy A, Xie Z, Kojima K, Vacanti CA, et al. Isoflurane decreases self-renewal capacity of rat cultured neural stem cells. Anesthesiology 2011;115:754-63.

45. Crampton SJ, Collins LM, Toulouse A, Nolan YM, O'Keeffe GW. Exposure of foetal neural progenitor cells to IL- $1 ß$ impairs their proliferation and alters their differentiation - A role for maternal inflammation? J Neurochem 2012;120:964-73.

46. Erasso DM, Chaparro RE, Quiroga Del Rio CE, Karlnoski R, Camporesi EM, Saporta S. Quantitative assessment of new cell proliferation in the dentate gyrus and learning after isoflurane or propofol anesthesia in young and aged rats. Brain Res 2012;1441:38-46.

47. Vutskits L, Gascon E, Tassonyi E, Kiss JZ. Effect of ketamine on dendritic arbor development and survival of immature GABAergic neurons in vitro. Toxicol Sci 2006;91:540-9.

48. De Roo M, Klauser P, Briner A, Nikonenko I, Mendez P, Dayer A, et al. Anesthetics rapidly promote synaptogenesis during a critical period of brain development. PLoS One 2009;4:e7043.
49. Briner A, Nikonenko I, De Roo M, Dayer A, Muller D, Vutskits L. Developmental Stage-dependent persistent impact of propofol anesthesia on dendritic spines in the rat medial prefrontal cortex. Anesthesiology 2011;115:282-93.

50. Vutskits L, Gascon E, Potter G, Tassonyi E, Kiss JZ. Low concentrations of ketamine initiate dendritic atrophy of differentiated GABAergic neurons in culture. Toxicology 2007;234:216-26.

51. Woodall AJ, Naruo $\mathrm{H}$, Prince DJ, Feng ZP, Winlow W, Takasaki M, et al. Anesthetic treatment blocks synaptogenesis but not neuronal regeneration of cultured Lymnaea neurons. J Neurophysiol 2003;90:2232-9.

52. Onizuka S, Takasaki M, Syed NI. Long-term exposure to local but not inhalation anesthetics affects neurite regeneration and synapse formation between identified lymnaea neurons. Anesthesiology 2005;102:353-63.

53. Lunardi N, Hucklenbruch C, Latham JR, Scarpa J, Jevtovic-Todorovic V. Isoflurane impairs immature astroglia development in vitro: The role of actin cytoskeleton. J Neuropathol Exp Neurol 2011;70:281-91.

54. Bartels M, Althoff RR, Boomsma DI. Anesthesia and cognitive performance in children: No evidence for a causal relationship. Twin Res Hum Genet 2009;12:246-53.

55. Sprung J, Flick RP, Wilder RT, Katusic SK, Pike TL, Dingli $\mathrm{M}$, et al. Anesthesia for cesarean delivery and learning disabilities in a population-based birth cohort. Anesthesiology 2009;111:302-10.

56. Wilder RT, Flick RP, Sprung J, Katusic SK, Barbaresi WJ, Mickelson C, et al. Early exposure to anesthesia and learning disabilities in a population-based birth cohort. Anesthesiology 2009;110:796-804.

57. Davidson AJ. Anesthesia and neurotoxicity to the developing brain: The clinical relevance. Paediatr Anaesth 2011;21:716-21.

58. DiMaggio C, Sun LS, Li G. Early childhood exposure to anesthesia and risk of developmental and behavioral disorders in a sibling birth cohort. Anesth Analg 2011;113:1143-51.

59. Hansen TG, Pedersen JK, Henneberg SW, Pedersen DA, Murray JC, Morton NS, et al. Academic performance in adolescence after inguinal hernia repair in infancy: A nationwide cohort study. Anesthesiology 2011;114:1076-85.

60. Ludman L, Spitz L, Wade A. Educational attainments in early adolescence of infants who required major neonatal surgery. J Pediatr Surg 2001;36:858-62.

61. Kalkman CJ, Peelen L, Moons KG, Veenhuizen M, Bruens M, Sinnema G, et al. Behavior and development in children and age at the time of first anesthetic exposure. Anesthesiology 2009;110:805-12.

62. Flick RP, Katusic SK, Colligan RC, Wilder RT, Voigt RG, Olson MD, et al. Cognitive and behavioral outcomes after early exposure to anesthesia and surgery. Pediatrics 2011;128:e1053-61.

63. Ing $\mathrm{C}$, DiMaggio $\mathrm{C}$, Whitehouse $\mathrm{A}$, Hegarty MK, Brady J, von Ungern-Sternberg BS, et al. Long-term differences in language and cognitive function after childhood exposure to anesthesia. Pediatrics 2012;130:e476-85.

64. Palanisamy A. Maternal anesthesia and fetal neurodevelopment. Int J Obstet Anesth 2012;21:152-62.

65. Hansen TG, Pedersen JK, Henneberg SW, Morton NS, Christensen K. Educational outcome in adolescence following pyloric stenosis repair before 3 months of age: A nationwide cohort study. Paediatr Anaesth 2013;23:883-90.

66. Davidson AJ, McCann ME, Morton NS, Myles PS. Anesthesia and outcome after neonatal surgery: The role for randomized trials. Anesthesiology 2008;109:941-4.

67. Sun LS, Li G, DiMaggio CJ, Byrne MW, Ing C, Miller TL, et al. Feasibility and pilot study of the Pediatric Anesthesia NeuroDevelopment Assessment (PANDA) project. J Neurosurg Anesthesiol 2012;24:382-8. 
68. Miller TL, Park R, Sun LS. Report of the third PANDA symposium on "Anesthesia and Neurodevelopment in Children”. J Neurosurg Anesthesiol 2012;24:357-61.

69. Dzietko M, Felderhoff-Mueser U, Sifringer M, Krutz B, Bittigau $\mathrm{P}$, Thor $\mathrm{F}$, et al. Erythropoietin protects the developing brain against $\mathrm{N}$-methyl-D-aspartate receptor antagonist neurotoxicity. Neurobiol Dis 2004;15:177-87.

70. Straiko MM, Young C, Cattano D, Creeley CE, Wang H, Smith DJ, et al. Lithium protects against anesthesia-induced developmental neuroapoptosis. Anesthesiology 2009;110:862-8.

71. Zhao L, Wang F, Gui B, Hua F, Qian Y. Prophylactic lithium alleviates postoperative cognition impairment by phosphorylating hippocampal glycogen synthase kinase-3ß (Ser9) in aged rats. Exp Gerontol 2011;46:1031-6.

72. Yon JH, Carter LB, Reiter RJ, Jevtovic-Todorovic V. Melatonin reduces the severity of anesthesia-induced apoptotic neurodegeneration in the developing rat brain. Neurobiol Dis 2006;21:522-30.

73. Wang C, Sadovova N, Patterson TA, Zou X, Fu X, Hanig JP, et al. Protective effects of 7-nitroindazole on ketamine-induced neurotoxicity in rat forebrain culture. Neurotoxicology 2008;29:613-20.

74. Zou X, Sadovova N, Patterson TA, Divine RL, Hotchkiss CE, Ali SF, et al. The effects of L-carnitine on the combination of, inhalation anesthetic-induced developmental, neuronal apoptosis in the rat frontal cortex. Neuroscience 2008;151:1053-65.

75. Edwards DA, Shah HP, Cao W, Gravenstein N, Seubert CN, Martynyuk AE. Bumetanide alleviates epileptogenic and neurotoxic effects of sevoflurane in neonatal rat brain. Anesthesiology 2010;112:567-75.

76. Lim BG, Shen FY, Kim YB, Kim WB, Kim YS, Han HC, et al. Possible role of GABAergic depolarization in neocortical neurons in generating hyperexcitatory behaviors during emergence from sevoflurane anesthesia in the rat. ASN Neuro 2014;6. pii: e00141.

77. Sanders RD, Sun P, Patel S, Li M, Maze M, Ma D. Dexmedetomidine provides cortical neuroprotection: Impact on anaesthetic-induced neuroapoptosis in the rat developing brain. Acta Anaesthesiol Scand 2010;54:710-6.

78. Degos V, Charpentier TL, Chhor V, Brissaud O, Lebon S, Schwendimann L, et al. Neuroprotective effects of dexmedetomidine against glutamate agonist-induced neuronal cell death are related to increased astrocyte brainderived neurotrophic factor expression. Anesthesiology 2013;118:1123-32.

79. Ma D, Williamson P, Januszewski A, Nogaro MC, Hossain M, Ong LP, et al. Xenon mitigates isoflurane-induced neuronal apoptosis in the developing rodent brain. Anesthesiology 2007;106:746-53.

80. Shu Y, Patel SM, Pac-Soo C, Fidalgo AR, Wan Y, Maze M, et al. Xenon pretreatment attenuates anesthetic-induced apoptosis in the developing brain in comparison with nitrous oxide and hypoxia. Anesthesiology 2010;113:360-8.

81. Men'shanov PN, Bannova AV, Il'inykh FA, Dygalo NN. Negative regulation of caspase- 3 expression in the neonatal cerebral cortex by alpha2A-adrenoceptors. Bull Exp Biol Med 2007;143:277-9.

82. Laudenbach V, Mantz J, Lagercrantz H, Desmonts JM, Evrard P, Gressens P. Effects of alpha(2)-adrenoceptor agonists on perinatal excitotoxic brain injury: Comparison of clonidine and dexmedetomidine. Anesthesiology 2002;96:134-41.

83. Cattano D, Williamson P, Fukui K, Avidan M, Evers AS, Olney JW, et al. Potential of xenon to induce or to protect against neuroapoptosis in the developing mouse brain. Can J Anaesth 2008;55:429-36.
84. Brosnan $\mathrm{H}$, Bickler PE. Xenon neurotoxicity in rat hippocampal slice cultures is similar to isoflurane and sevoflurane. Anesthesiology 2013;119:335-44.

85. Turner CP, Gutierrez S, Liu C, Miller L, Chou J, Finucane B, et al. Strategies to defeat ketamine-induced neonatal brain injury. Neuroscience 2012;210:384-92.

86. Wei $H$, Liang $G$, Yang $H$. Isoflurane preconditioning inhibited isoflurane-induced neurotoxicity. Neurosci Lett 2007;425:59-62.

87. Zhou XF, Huang DD, Wang DF, Fu JQ. The protective effect of propofol pretreatment on glutamate injury of neonatal rat brain slices. Zhongguo Wei Zhong Bing Ji Jiu Yi Xue 2012;24:750-3.

88. Anand KJ, Garg S, Rovnaghi CR, Narsinghani U, Bhutta AT, Hall RW. Ketamine reduces the cell death following inflammatory pain in newborn rat brain. Pediatr Res 2007;62:283-90.

89. Ullah N, Ullah I, Lee HY, Naseer MI, Seok PM, Ahmed J, et al. Protective function of nicotinamide against ketamine-induced apoptotic neurodegeneration in the infant rat brain. J Mol Neurosci 2012;47:67-75.

90. Lema Tomé CM, Bauer C, Nottingham C, Smith C, Blackstone K, Brown L, et al. MK801-induced caspase-3 in the postnatal brain: Inverse relationship with calcium binding proteins. Neuroscience 2006;141:1351-63.

91. Naseer MI, Ullah N, Ullah I, Koh PO, Lee HY, Park MS, et al. Vitamin C protects against ethanol and PTZ-induced apoptotic neurodegeneration in prenatal rat hippocampal neurons. Synapse 2011;65:562-71.

92. Konishi Y, Chui DH, Hirose H, Kunishita T, Tabira T. Trophic effect of erythropoietin and other hematopoietic factors on central cholinergic neurons in vitro and in vivo. Brain Res 1993;609:29-35.

93. Tsuchimoto T, Ueki M, Miki T, Morishita J, Maekawa N. Erythropoietin attenuates isoflurane-induced neurodegeneration and learning deficits in the developing mouse brain. Paediatr Anaesth 2011;21:1209-13.

94. Kumral A, Yesilirmak DC, Sonmez U, Baskin H, Tugyan K, Yilmaz $\mathrm{O}$, et al. Neuroprotective effect of the peptides ADNF-9 and NAP on hypoxic-ischemic brain injury in neonatal rats. Brain Res 2006;1115:169-78.

95. Zhang Y, Dong Y, Xu Z, Xie Z. Propofol and magnesium attenuate isoflurane-induced caspase-3 activation via inhibiting mitochondrial permeability transition pore. Med Gas Res 2012;2:20.

96. Brambrink AM, Evers AS, Avidan MS, Farber NB, Smith DJ, Zhang X, et al. Isoflurane-induced neuroapoptosis in the neonatal rhesus macaque brain. Anesthesiology 2010;112:834-41.

97. Paule MG, Li M, Allen RR, Liu F, Zou X, Hotchkiss C, et al. Ketamine anesthesia during the first week of life can cause long-lasting cognitive deficits in rhesus monkeys. Neurotoxicol Teratol 2011;33:220-30.

98. BrambrinkAM, BackSA, RiddleA, Gong X, MoravecMD, Dissen GA, et al. Isoflurane-induced apoptosis of oligodendrocytes in the neonatal primate brain. Ann Neurol 2012;72:525-35.

99. Brambrink AM, Evers AS, Avidan MS, Farber NB, Smith DJ, Martin LD, et al. Ketamine-induced neuroapoptosis in the fetal and neonatal rhesus macaque brain. Anesthesiology 2012;116:372-84.

100. Creeley CE, Dikranian KT, Dissen GA, Back SA, Olney JW, Brambrink AM. Isoflurane-induced apoptosis of neurons and oligodendrocytes in the fetal rhesus macaque brain. Anesthesiology 2014;120:626-38.

How to cite this article: Durga P, Yalamanchili V. Basic cellular and molecular mechanisms of anesthetic-induced developmental neurotoxicity: Potential strategies for alleviation. J Neuroanaesthesiol Crit Care 2016;3:15-24

Source of Support: Nil, Conflict of Interest: None declared. 